Mourrut.-Rhenmatoid Arthritis and Pseudo-Rheumatism of the Laryn.r. "Archives Internationale de Laryngologie, d'Otologie, et de Rhinologie," July, August, 1902.

Dr. Mourrat believes that this condition is often overlooked, and. in addition to causing considerable functional disturbance, may lead to permanent impairment of the movements of the larynx.

It is often met with after influenza, and calls for prompt treatment. Anthony IIcCall.

\title{
THYROID AND TRACHEA.
}

Olmsted, Ingersoll.-The Operative Treatment of Goitre. "Canadiun Journal of Medicine and Surgery," October, 1902.

This is a report of twelve cases operated on. The average stay in the hospital was seven days, and the resulting scar slight. The operation advised is the one usually performed by Kocher, and is done under cocaine anæsthesia.

Operation is recommended when any of the following conditions occur: when danger arises from dyspnoea, inflammatory changes, or suspicion of malignancy; when the enlarged thyroid threatens to enter the thorax; when the goitre has reached considerable development from the formation of a single colloid node; when symptoms of the presence of Basedow's disease appear.

Price-Brou'n.

\section{ESOPHAGUS.}

Hamilton, George.-Removal of Foreign Bodies from the Esophagus lu! an Improved Methorl of Using the Roentgen Rays. "British Medical Journal," February 7, 1900.

The coin-catcher is passed down whilst the patient is seated on a chair, the Roentgen rays being placed behind him. In the case of a child aged two and a quarter years, who had swallowed a halfpenny five days previously, the following plan was adopted: The child was placed in the horizontal position on the canvas couch. When the tube was placed below the couch the halfpenny was seen behind the second piece of the sternum.

Under chloroform the coin-catcher was passed, and seen by means of the screen to go 2 to 3 inches beyond the coin. The hook was now carefully adjusted to the middle of the coin, when a rapid and successful extraction was effected.

W. Milligan.

Riviere, Clive.-Perforation of the Esophagus by Tuberculous Glancls. "British Medical Journal," January 24, 1903.

The writer describes three such cases, the first occurring in a male child aged two years, the second in a male child aged ten months, and the third in a male child aged one year and eleven months.

In these three cases the gland (or glands) affected was situated below the bifurcation of the trachea. In two of the cases the gland had completely emptied its caseous contents, the cavity having a smooth wall, and apparently a mucous lining. The author is inclined to think that many cases of cesophageal diverticulum occurring in this situation are due primarily to tuberculous disease of the "bifurcation gland."

IV. Milligan. 